\title{
Desempenho das mudas de mangue em uma área impactada na Península de Ajuruteua - Norte do Brasil
}

Os manguezais vêm sofrendo redução significativa na sua extensão ao longo dos anos e a principais ameaças a esse ecossistema são o desmatamento para produção de carvão, conversão das suas terras para áreas em exploração com aquicultura, construções de obras civis, rodovias e outros usos. Em função desses impactos ambientais negativos, muitos trabalhos surgem com o propósito de recuperar esses ecossistemas. A pesquisa teve o objetivo de avaliar e associar a sobrevivência e o crescimento das mudas de Rhizophora mangle L., Avicennia germinans (L) L. e Laguncularia racemosa (L.) C.F. Gaertn com os atributos físicoquímicos de um solo impactado. O experimento foi instalado na rodovia PA 458 do KM 17, no município de Bragança-PA. 0 delineamento experimental utilizado foi o de blocos ao acaso, com 3 tratamentos e 6 repetições. Cada parcela experimental foi constituída de 20 mudas, espaçadas por 1,0 m entre plantas e 1,0 $\mathrm{m}$ entre linhas. Os dados foram analisados pelo pacote estatístico Primer ${ }^{\circledast} 6$, nos dados abióticos foram aplicados à Análise dos Componentes Principais (PCA). A relação entre os dados bióticos e abióticos, foi realizada através procedimento BIOENV que calcula o coeficiente de correlação de Spearman. Os resultados mostraram que as condições físico-químicas do solo associada ao baixo índice pluviométrico registrado no período seco na região se constituíram em fatores limitantes e influenciaram negativamente a sobrevivência e o crescimento das espécies, e explicaram a razão pela qual a mortalidade das mudas foi crescente ao longo do ano na área experimental.

Palavras-chave: Solo; Nutrientes; Sobrevivência; Manguezal.

\section{Performance of mangue seedlings in an impacted area in Peninsula Ajuruteua - Northern of Brazil}

\begin{abstract}
Mangrove extension has been suffering a significant reduction over the years and the main threats to this ecosystem are deforestation for coal production, land conversion for aquaculture, construction of civil works, highways, and other uses. Due to these negative environmental impacts, many studies have been conducted with the purpose of rehabilitating these ecosystems. The aim of this study is to relate the survival and growth of Avicennia germinans (L.) Stearn, Rhizophora mangle L. and Laguncularia racemosa (L.) Gaertn. F. seedlings with the physico-chemical properties of degraded soils. The experiment was conducted on PA-458 highway, km 17, in the municipality of Bragança, Pará, Brazil. Experimental design consisted in random blocks with 3 treatments ( 3 species) and 6 replicates. Each plot consisted of 20 plants with spacing of $1.0 \mathrm{~m}$ between plants and rows. Data were analyzed using the PRIMER v6 software. Principal Component Analysis (PCA) was applied to abiotic variables and the relationship between biotic and abiotic data was established using the BIOENV procedure, which calculated Spearman's correlation coefficient. Our results showed that the physico-chemical conditions of the soil associated to low rainfall during dry season in the region are limiting factors, and negatively influenced survival and growth of species, thus explaining why seedling mortality increased throughout the year in the experimental area.
\end{abstract}

Keywords: Soil; Nutrients; Seedling; Mangrove.

Topic: Ciências Florestais

Reviewed anonymously in the process of blind peer.
Received: 03/07/2021

Approved: $27 / 07 / 2021$
Erneida Coelho Araujo (D)

Universidade Federal do Pará, Brasil

http://lattes.cnpq.br/6971929506671334

http://orcid.org/0000-0003-2841-9973

erneida@ufpa.br

Lidiane Ferreira Gomes

Universidade Federal do Pará, Brasil

http://lattes.cnpq.br/4200842409480801

lidianeloyola@hotmail.com

Claudia Patricia Soares Arruda

Universidade Federal do Pará, Brasil

claudia.patricia.4@hotmail.com
Referencing this:

ARAÚJO, E. C.; GOMES, L. F.; ARRUDA, C. P. S.. Desempenho das mudas de mangue em uma área impactada na Península de Ajuruteua - Norte do Brasil. Revista Ibero Americana de Ciências Ambientais, v.12, n.7, p.93-104, 2021. DOI: http://doi.org/10.6008/CBPC21796858.2021 .007 .0009 


\section{INTRODUÇÃO}

Os manguezais são considerados referências das zonas tropicais e subtropicais, sendo influenciados diretamente pelas marés, localizam-se na zona de transição entre os ambientes terrestre e marinho. São compostos por espécies vegetais típicas, além de micro e macroalgas, adaptadas a flutuação de salinidade. Estão presentes em zonas abrigadas nas áreas costeiras onde ocorrem condições propícias para alimentação, proteção e nidificação de muitas espécies animais, são considerados ainda como importantes transformadores de nutrientes em matéria orgânica e geradores de bens e serviços (SCHAEFFER-NOVELLI, 1995).

No Brasil, os manguezais estão distribuídos desde o extremo norte do Amapá até Santa Catarina com predominância no Pará e Maranhão, sendo que no Nordeste do Ceará e Bahia esse ecossistema tem grande significância (DIEGUES, 2001). O Brasil apresenta a segunda maior área de manguezal do mundo com cerca $13.000 \mathrm{~km}^{2}$, correspondendo a 8,5\% do total mundial, perdendo apenas para a indonésia com $31.894 \mathrm{~km}^{2}$ (SPALDING et al., 2010).

A Península costeira Bragantina possui uma linha de costa com $40 \mathrm{~km}$ que vai da ponta de Maiaú até a foz do rio Caeté, o manguezal de Bragança-PA tem uma distância de cerca de $150 \mathrm{~km}$ e se estende até o sul do Rio Amazonas (SOUZA FILHO, 2005). Os manguezais de macro marés do Noroeste do Maranhão e noroeste do Pará estendem-se da baia de Marajó, até a ponta de tubarão, baía de São José, no Maranhão, com 650 km de linha reta de litoral (LACERDA, 1999), sendo que no Pará são 2.177 km² (SOUZA FILHO, 2005). Na década de 70 foi construída a rodovia PA - 458 que liga Bragança a praia de Ajuruteua. A estrada facilitou o acesso a essa praia que até então era realizado somente por via fluvial. No entanto a referida estrada teve seu custo ambiental, causando impactos negativos ao longo da construção. A estrada cortou $26 \mathrm{~km}$ da floresta de manguezal, separando em dois lados, um lado passou a ter menos influência das marés do que o outro. Depois dessa construção, o lado oeste - com menor influência das marés - teve $3,4 \mathrm{~km}^{2}$ de área degradada, sendo difícil até a recuperação dessa área pela falta de água. Os manguezais em questão recebem influência dos rios taperuçu e caeté, mas com a construção da rodovia, permaneceram apenas seis furos, são: furo da Taicí, Estiva, Grande, Ostra, Chato e Café (FERNANDES et al., 2007).

É importante ressaltar que a costa nordeste do estado do Pará a noroeste do Maranhão apresenta uma baixa diversidade das espécies arbóreas de manguezais, sendo contraposta a grande variabilidade espacial em resposta as condições locais de inundação e salinidade (PROST et al., 1996). A Variação fitoespacial é um bom exemplo dos manguezais que resistem em diferentes condições do meio, variando de alta salinidade até a baixa salinidade recebendo água de rio (MENEZES et al., 2005). Na península de Ajuruteua, as três espécies arbóreas mais encontradas são: Rhizophora mangle L., Avicennia germinans (L) L. e Laguncularia racemosa (L.) C.F. Gaertn (ABREU et al., 2006).

Ao longo dos anos, esse ecossistema vem sofrendo redução significativa na sua extensão e a principal ameaça aos manguezais é o desmatamento para produção de carvão e conversão das suas terras para áreas em exploração com aquicultura, construções de obras civis e outros usos (VRIES, 2003). Em função desses 
impactos negativos, muitos trabalhos surgem com o propósito de recuperar esses ecossistemas.

Os primeiros trabalhos de recuperação de manguezal no Brasil aconteceram nos estados da Bahia, Rio de Janeiro e São Paulo (OLIVEIRA, 1975), o autor elaborou uma série de publicações da Baía de Guanabara que recomendavam o plantio de espécies arbóreas de mangue. No Japão, Warushima et al. (1994) realizaram pesquisa com o plantio de propágulos de Kandelia candel, Bruguiera gymnorthiza e Rhizophora stylosa, os propágulos foram semeados no campo em solos com pH distintos, houve o acompanhamento do crescimento e desenvolvimento das espécies para verificar em qual solo elas melhor se adaptaram. O melhor desenvolvimento delas se deu em solo similar ao seu habitat natural. No Paquistão, Queresh (1990) utilizou espécies nativas e exóticas para a restauração dos bosques. Assim o objetivo da investigação foi avaliar e associar a sobrevivência e o crescimento das mudas de Rhizophora mangle L., Avicennia germinans (L) L. e Laguncularia racemosa (L.) C.F. Gaertn em relações as condições físico-químicas de uma área impactada no norte do Brasil.

\section{MATERIAIS E MÉTODOS}

\section{Caracterização da área experimental}

O estudo foi realizado na rodovia PA 458 do Km 17 (005'6,3"S e 04642'12,9”W), a mesma se estende de Bragança à praia de Ajuruteua, cortando $26 \mathrm{~km}$ de florestas de mangue (LARA et al., 2003). 0 aterramento de alguns canais (furos) para a construção da rodovia parece ter sido um dos principais fatores a desencadear o processo de ressecamento do sedimento sob os bosques de mangue, via a interrupção permanente do fluxo das marés na área de estudo no Km 17. Em consequência, uma grande área, às margens dessa rodovia no lado oeste, ficou praticamente sem cobertura vegetal (FERNANDES et al., 2007).
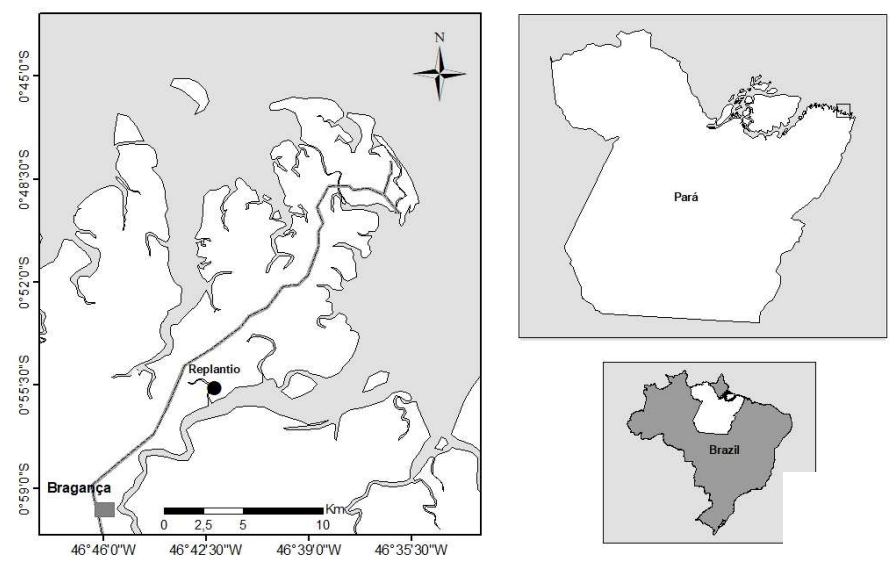

Figura 1: Área de estudo no Km 17 (área degradada), lado leste do estado do Pará (Repalntio), mapa do Brasil modificado. Fonte: Fernandes et al. (2007)

\section{Clima da região e regime de maré}

O clima da região é quente e úmido, com uma estação seca distinta, de julho a dezembro, e uma estação chuvosa, Entre janeiro e junho, com precipitação média anual entre 2500 mm e 3000 mm, e temperaturas médias de aproximadamente $26^{\circ} \mathrm{C}$ (MORAES et al., 2005). Os rios são caracterizados por um regime macro-maré semidiurno, com Maré de mais de $5 \mathrm{~m}$ de altura. 
A Precipitação Pluviométrica (Figura 2) mostra que as chuvas mais intensas ocorreram no período de fevereiro a julho de 2011. No período de agosto a dezembro de 2011 e fevereiro de 2012, o índice pluviométrico foi menor. A precipitação pluviométrica anual foi de $2.345 .1 \mathrm{~mm}$, e os valores foram fornecidos pela estação Meteorológica de Tracuateua, Pará (INMET, 2012).

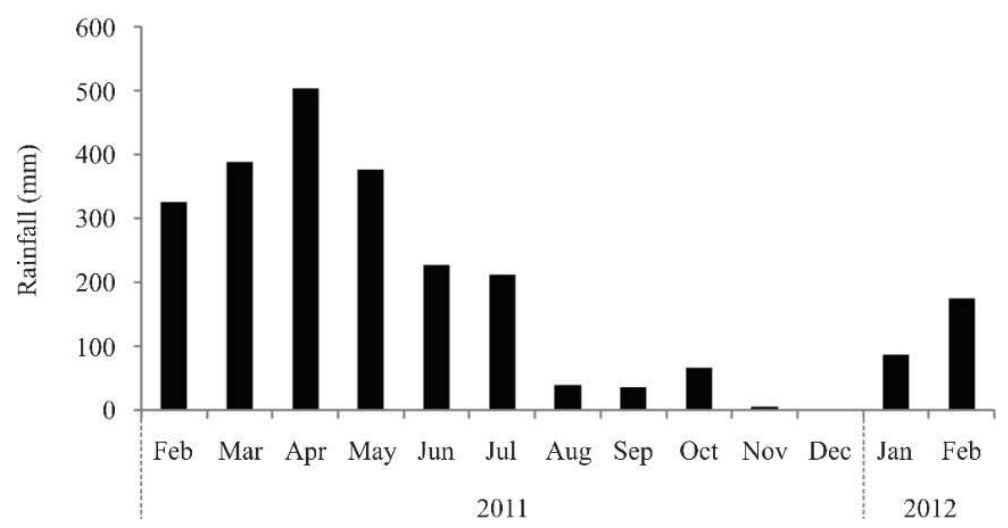

Figura 2: Valores mensais de precipitação pluviométrica registrados durante a condução do experimento (Fev./2011 a Fev./2102).

\section{Espécies utilizadas e manutenção do plantio}

As mudas das três espécies arbóreas de mangue ( $R$. mangle, $A$. germinans, e L. racemosa) foram retiradas de um viveiro localizado na comunidade de Tamatateua (Bragança-PA) e transplantadas no período chuvoso para parcelas instaladas na rodovia PA do Km 17. As mudas foram implantadas em covas de dimensões 0,30 $\mathrm{m} \times 0,30 \mathrm{~m} \times 0,30 \mathrm{~m}$, o espaçamento utilizado foi de $1 \mathrm{~m} \times 1 \mathrm{~m}$, entre linhas e plantas.

A coleta do solo foi realizada bimestralmente. A sobrevivência e crescimento em altura das mudas também foram avaliadas bimestralmente (fev./2011 a fev./2012) compreendendo o período chuvoso e período seco. Utilizou-se o delineamento de blocos ao acaso, com 3 tratamentos (três espécies) e 6 repetições, cada parcela continha 20 mudas, 120 mudas por bloco, totalizando 360 mudas.

\section{Sobrevivência e Crescimento em altura}

A sobrevivência foi determinada com base na quantidade das mudas avaliadas no início e ao final no experimento, assim como o crescimento e altura das mudas. A avaliação do crescimento em altura foi realizada com o auxílio de uma régua $(100 \mathrm{~cm})$, a altura da parte aérea foi determinada a partir do nível do substrato até a ponta da última folha e o diâmetro o coleto foi calculado ao nível do substrato.

\section{Análises físico-químicas}

A coleta das amostras de solo na área experimental foi realizada no período chuvoso e seco, e realizada a $20 \mathrm{~cm}$ de profundidade, com o uso do trado, totalizando três amostras mensais em cada bloco, durante a condução da pesquisa. Em cada amostra de solo foram analisados os seguintes parâmetros: granulometria (areia, silte e argila), macronutrientes (P, Na, K, Ca, Mg, M.O, Ph, C org) e micronutrientes ( $\mathrm{Cu}$, $\mathrm{Fe}, \mathrm{Mn}, \mathrm{Zn}$ ), sendo posteriormente encaminhadas ao laboratório da Universidade Federal Rural da Amazônia (UFRA) para que fossem realizadas as análises físico químicas das amostras de solo. 


\section{Análises de Dados}

Os dados foram analisados pelo pacote estatístico (Plymouth Routines In Multivariate Ecological Research) Primer $^{\circledR}$ 6, para avaliar se houve diferenças significativas entre os meses avaliados. Utilizou-se a análise multivariada não paramétrica de similaridade (ANOSIM) com a matriz de similaridade calculada pelo índice de similaridade de Bray-Curtis. Nos dados abióticos foram aplicados à Análise dos Componentes Principais (PCA). A relação entre os dados bióticos e abióticos, por local de coleta, foi estabelecida utilizando o procedimento BIOENV que calcula o coeficiente de correlação de Spearman.

\section{RESULTADOS}

\section{Análises físico-químicas}

As análises físico-químicas das amostras de solo da área experimental são apresentadas na tabela 1.

Tabela 1: As análises físico-químicas das amostras de solo da área experimental.

\begin{tabular}{|c|c|c|c|c|c|c|c|c|c|c|c|c|c|c|c|}
\hline $\begin{array}{l}\text { Mont } \\
\mathrm{h}\end{array}$ & $\begin{array}{l}\text { Blo } \\
\text { ck }\end{array}$ & PH & OC & $\mathbf{P}$ & $\mathrm{Na}$ & $\mathrm{K}$ & $\mathrm{Ca}$ & $\mathrm{Cu}$ & $\mathrm{Fe}$ & $M n$ & $\mathrm{Zn}$ & OM & Sand & Silt & Clay \\
\hline April & & 7.4 & 9.79 & 9.05 & 2.8 & $\begin{array}{l}3.3 \\
2\end{array}$ & $\begin{array}{l}20 . \\
78\end{array}$ & 1.9 & 1222.9 & 119.8 & 7.9 & $\begin{array}{l}0.0 \\
9\end{array}$ & 23 & 29 & 48 \\
\hline June & $\begin{array}{l}\text { Blo } \\
\text { ck }\end{array}$ & 6.6 & 13.3 & 47.75 & $\begin{array}{l}2.6 \\
2 \\
\end{array}$ & $\begin{array}{l}4.3 \\
9 \\
\end{array}$ & 20 & 1.5 & 1600.9 & 169.4 & 7.8 & $\begin{array}{l}0.0 \\
9 \\
\end{array}$ & 26 & 32 & 42 \\
\hline $\begin{array}{l}\text { Augu } \\
\text { st }\end{array}$ & I & 7 & 12.1 & 52.25 & $\begin{array}{l}3.4 \\
2 \\
\end{array}$ & $\begin{array}{l}4.2 \\
9 \\
\end{array}$ & $\begin{array}{l}24 . \\
78 \\
\end{array}$ & 1.7 & 1549.1 & 124.3 & 6.4 & $\begin{array}{l}0.0 \\
9 \\
\end{array}$ & 58 & 13 & 29 \\
\hline $\begin{array}{l}\text { Octob } \\
\text { er }\end{array}$ & & $\begin{array}{l}6.6 \\
4 \\
\end{array}$ & 13.3 & 10.53 & $\begin{array}{l}3.8 \\
5 \\
\end{array}$ & $\begin{array}{l}4.3 \\
3 \\
\end{array}$ & $\begin{array}{l}27 . \\
38\end{array}$ & 1.3 & 1764.1 & 81.5 & 6.8 & $\begin{array}{l}0.0 \\
9 \\
\end{array}$ & 29 & 29 & 42 \\
\hline $\begin{array}{l}\text { Dece } \\
\text { mber }\end{array}$ & & 6.6 & 11.3 & 89.03 & $\begin{array}{l}3.4 \\
8 \\
\end{array}$ & 7.8 & $\begin{array}{l}27 . \\
8 \\
\end{array}$ & 1.3 & 1765.3 & 146 & 6.6 & $\begin{array}{l}0.0 \\
9 \\
\end{array}$ & 47 & 19 & 34 \\
\hline $\begin{array}{l}\text { Febru } \\
\text { ary }\end{array}$ & & 7.3 & 10.1 & 95.01 & $\begin{array}{l}2.9 \\
8 \\
\end{array}$ & $\begin{array}{l}6.0 \\
5 \\
\end{array}$ & $\begin{array}{l}27 . \\
61 \\
\end{array}$ & 1.3 & 1259 & 171.3 & 6.8 & $\begin{array}{l}0.0 \\
9 \\
\end{array}$ & 26 & 21 & 53 \\
\hline Mean , \pm & DP & $\begin{array}{l}5.2 \\
6 \\
\pm \\
2,6 \\
9\end{array}$ & $\begin{array}{l}10.92 \\
\pm 4,96\end{array}$ & $\begin{array}{l}46.74 \\
\pm 21,26\end{array}$ & $\begin{array}{l}2.7 \\
6, \\
\pm \\
1,0 \\
3\end{array}$ & $\begin{array}{l}3.9 \\
7, \\
\pm \\
1,5 \\
7 \\
\end{array}$ & $\begin{array}{l}22 . \\
53, \\
\pm \\
9,7 \\
4\end{array}$ & $\begin{array}{l}1.1 \\
0, \\
\pm \\
0,5 \\
7 \\
\end{array}$ & $\begin{array}{l}\text { 1235.21, } \\
\pm 571,93\end{array}$ & $\begin{array}{l}93.16 \\
\pm 46,49\end{array}$ & $\begin{array}{l}6.0 \\
6, \\
\pm \\
2,8 \\
4 \\
\end{array}$ & $\begin{array}{l}0.0 \\
7, \\
\pm \\
0,0 \\
4 \\
\end{array}$ & $\begin{array}{l}26.70 \\
\pm 10,40\end{array}$ & $\begin{array}{l}22 . \\
69 \\
\pm 10, \\
49\end{array}$ & $\begin{array}{l}31.95 \\
\pm \\
14,83\end{array}$ \\
\hline April & & $\begin{array}{l}7.3 \\
4 \\
\end{array}$ & 11.3 & 41.34 & $\begin{array}{l}2.5 \\
3 \\
\end{array}$ & $\begin{array}{l}3.2 \\
2 \\
\end{array}$ & $\begin{array}{l}18 . \\
78\end{array}$ & 1.4 & 1517.9 & 159.7 & 8.1 & $\begin{array}{l}0.0 \\
9 \\
\end{array}$ & 17 & 30 & 53 \\
\hline June & $\begin{array}{l}\text { Blo } \\
\text { ck }\end{array}$ & 7.1 & 12.7 & 34.16 & $\begin{array}{l}2.2 \\
4 \\
\end{array}$ & $\begin{array}{l}2.8 \\
3 \\
\end{array}$ & $\begin{array}{l}16 . \\
68\end{array}$ & 1.4 & 1269.9 & 109.5 & 6.8 & $\begin{array}{l}0.0 \\
9 \\
\end{array}$ & 36 & 27 & 37 \\
\hline $\begin{array}{l}\text { Augu } \\
\text { st }\end{array}$ & II & 6.9 & 11.3 & 43.72 & $\begin{array}{l}3.5 \\
9 \\
\end{array}$ & $\begin{array}{l}4.5 \\
9 \\
\end{array}$ & $\begin{array}{l}22 . \\
73\end{array}$ & 1.4 & 1536.1 & 134 & 6.6 & $\begin{array}{l}0.0 \\
9 \\
\end{array}$ & 20 & 32 & 48 \\
\hline $\begin{array}{l}\text { Octob } \\
\text { er }\end{array}$ & & 6.9 & 11.7 & 42.53 & $\begin{array}{l}2.8 \\
7 \\
\end{array}$ & $\begin{array}{l}6.5 \\
4 \\
\end{array}$ & $\begin{array}{l}19 . \\
32\end{array}$ & 1.1 & 1287.3 & 99.8 & 5.7 & $\begin{array}{l}0.0 \\
9 \\
\end{array}$ & 32 & 26 & 42 \\
\hline $\begin{array}{l}\text { Dece } \\
\text { mber }\end{array}$ & & 6.6 & 10.9 & 50.15 & $\begin{array}{l}3.0 \\
8 \\
\end{array}$ & $\begin{array}{l}6.3 \\
4 \\
\end{array}$ & $\begin{array}{l}29 . \\
76\end{array}$ & 1.1 & 1321.9 & 108.1 & 6 & $\begin{array}{l}0.0 \\
9 \\
\end{array}$ & 10 & 35 & 55 \\
\hline $\begin{array}{l}\text { Febru } \\
\text { ary }\end{array}$ & & 6.8 & 13.3 & 52.25 & $\begin{array}{l}3.9 \\
7 \\
\end{array}$ & 3.3 & $\begin{array}{l}29 . \\
87\end{array}$ & 1.3 & 1486.5 & 116.4 & 6.5 & $\begin{array}{l}0.0 \\
9 \\
\end{array}$ & 23 & 35 & 42 \\
\hline Mean , \pm & DP & $\begin{array}{l}6.3 \\
1, \\
\pm \\
1,4 \\
4 \\
\end{array}$ & $\begin{array}{l}10.81 \\
\pm 2,45\end{array}$ & $\begin{array}{l}45.88 \\
\pm 29,21\end{array}$ & $\begin{array}{l}2.8 \\
3, \\
\pm \\
0,7 \\
8 \\
\end{array}$ & $\begin{array}{l}4.3 \\
3, \\
\pm \\
1,7 \\
3 \\
\end{array}$ & $\begin{array}{l}22 . \\
16, \\
\pm \\
5,7 \\
2 \\
\end{array}$ & $\begin{array}{l}1.3 \\
4, \\
\pm \\
0,3 \\
5 \\
\end{array}$ & $\begin{array}{l}1387.37 \\
\pm 352,39\end{array}$ & $\begin{array}{l}\text { 123.52, } \\
\pm 40,84\end{array}$ & $\begin{array}{l}6.5 \\
9, \\
\pm \\
1,4 \\
9 \\
\end{array}$ & $\begin{array}{l}0.0 \\
8, \\
\pm \\
0,0 \\
2 \\
\end{array}$ & $\begin{array}{l}29.23 \\
\pm 13,96\end{array}$ & $\begin{array}{l}22 . \\
91, \\
\pm \\
7,41\end{array}$ & $\begin{array}{l}38.64 \\
\pm 11,79\end{array}$ \\
\hline April & & 7.2 & 12.5 & 37.65 & $\begin{array}{l}3.0 \\
8\end{array}$ & $\begin{array}{l}3.4 \\
1\end{array}$ & $\begin{array}{l}19 . \\
51\end{array}$ & 1.7 & 1397.9 & 116.8 & 8.9 & $\begin{array}{l}0.0 \\
9\end{array}$ & 14 & 31 & 55 \\
\hline June & $\begin{array}{l}\text { Blo } \\
\text { ck }\end{array}$ & 6.8 & 13.7 & 31.96 & $\begin{array}{l}2.2 \\
3 \\
\end{array}$ & 3.9 & $\begin{array}{l}19 . \\
82\end{array}$ & 1.3 & 1678.1 & 107.7 & 9.3 & $\begin{array}{l}0.0 \\
9 \\
\end{array}$ & 23 & 29 & 48 \\
\hline $\begin{array}{l}\text { Augu } \\
\text { st }\end{array}$ & III & 7 & 11.7 & 44.73 & 0 & 4.2 & $\begin{array}{l}25 . \\
07\end{array}$ & 1,4 & 1571,4 & 110,15 & 8,6 & $\begin{array}{l}0.0 \\
9 \\
\end{array}$ & 20 & 32 & 48 \\
\hline $\begin{array}{l}\text { Octob } \\
\text { er }\end{array}$ & & 6.7 & 11.3 & 45.92 & $\begin{array}{l}3.0 \\
9\end{array}$ & $\begin{array}{l}4.8 \\
8\end{array}$ & $\begin{array}{l}21 . \\
66\end{array}$ & 1.2 & 1401.9 & 154.3 & 5.8 & $\begin{array}{l}0.0 \\
9\end{array}$ & 26 & 32 & 42 \\
\hline $\begin{array}{l}\text { Dece } \\
\text { mber }\end{array}$ & & 5.8 & 17.2 & 44.93 & $\begin{array}{l}3.4 \\
7\end{array}$ & 7.8 & $\begin{array}{l}25 . \\
37\end{array}$ & 1.5 & 1575.4 & 171.9 & 6 & $\begin{array}{l}0.0 \\
9\end{array}$ & 26 & 29 & 45 \\
\hline
\end{tabular}




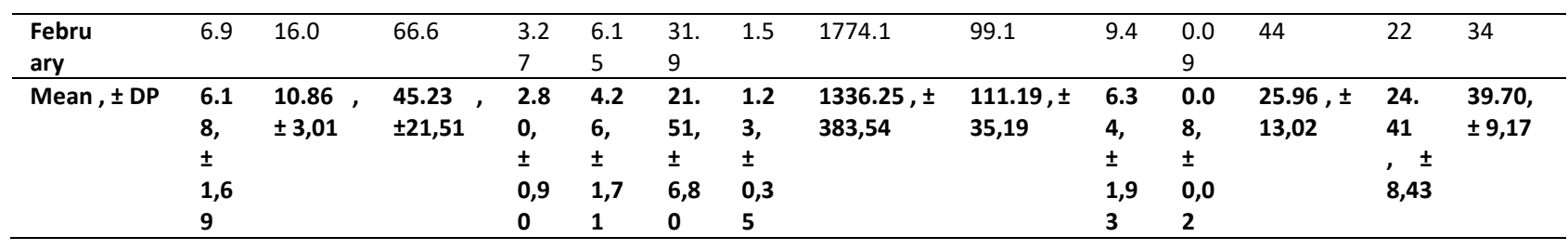

\section{Sobrevivência e Crescimento em altura}

Ao se comparar os blocos pela análise de similaridade (Anosim) não se observou diferença significativa (ANOSIM R= - 0,004; $p=0,45$ ) entre os mesmos quando se avaliou a sobrevivência. Para o fator mês houve diferença significativa ( $A N O S I M R=0,5 ; p=0,01$ ).

A Anosim foi realizada para os três blocos e se observou que não houve diferença significativa entre os blocos (ANOSIM R; 0,04; $p=0,17$ ). A Anosim (análise de similaridade) foi realizada para cada grupo entre os diferentes meses, e se constatou que a variação foi significativa (ANOSIM R; 0,302; $p=0,001$ ) para o crescimento em altura.

\section{Componentes Principais PCA}

A análise de componentes principais (PCA) foi utilizada para obter a correlação entre as variáveis abióticas nos blocos.

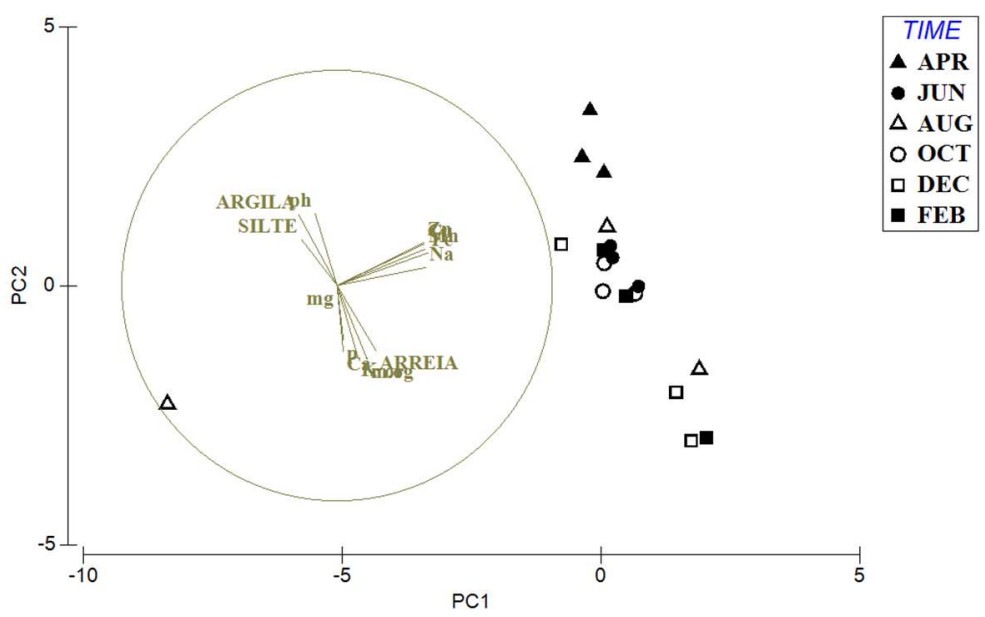

Figura 3: Ordenação do PCA do solo de manguezal PC1 e PC2 explicam 35,8\% e 23,4\% da variação, respectivamente, durante o período de chuva (símbolos fechados) e seco (símbolos abertos) de 2011 na área experimental, BragançaPA.

O primeiro e o segundo eixos da PCA foram responsáveis por $59,2 \%$ da variância dos dados abióticos. As contribuições das variáveis aos eixos desta análise mostram que o primeiro eixo foi influenciado positivamente pelos elementos $\mathrm{Na}$, Fe e $\mathrm{Mn}$. O segundo eixo, responsável por $35,8 \%$ da distribuição teve maior contribuição positiva do $\mathrm{Ph}$, silte e argila.

Tabela 2: Tabela de Contribuição das variáveis aos dois primeiros componentes do PCA para solo de mangue, área experimental do km 17, Bragança-Pa.

\begin{tabular}{lll}
\hline Variabilidade & PC1 & PC2 \\
\hline Ph & $-0,102$ & $\mathbf{0 , 3 3 6}$ \\
C org & 0,140 & $-0,342$ \\
m.o & 0,140 & $-0,342$ \\
P & 0,030 & $-0,255$
\end{tabular}




\begin{tabular}{llc}
$\mathrm{Na}$ & $\mathbf{0 , 4 1 4}$ & 0,084 \\
$\mathrm{~K}$ & 0,097 & $-0,333$ \\
$\mathrm{Ca}$ & 0,029 & 0,308 \\
$\mathrm{Cu}$ & 0,405 & 0,193 \\
$\mathrm{Fe}$ & $\mathbf{0 , 4 2 4}$ & 0,170 \\
$\mathrm{Mn}$ & 0,412 & 0,199 \\
$\mathrm{Zn}$ & $\mathbf{0 , 4 0 4}$ & 0,000 \\
$\mathrm{Mg}$ & 0,000 & $-0,304$ \\
Areia & 0,182 & 0,215 \\
Silte & $-0,166$ & 0,328 \\
Argila & $-0,178$ & 3,27 \\
\hline Auto valor & 5,01 & 23,4 \\
\hline \% Explicação & 35,8 & $\mathbf{5 9 , 2}$ \\
\hline Explicação acumulada & $\mathbf{3 5 , 8}$ \\
\hline
\end{tabular}

Análise de correlação entre fatores bióticos e abióticos

A análise BEST/BIOENV foi usada para obter uma correlação entre as variáveis abióticas e as variáveis bióticas: sobrevivência e crescimento em altura. Para o crescimento em altura os elementos que mais contribuíram foram o potássio (K) e cálcio (Ca). Quanto a variável sobrevivência o elemento sódio (Na), cobre (Cu) e zinco (Zn) associados positivamente, tiveram maior contribuição.

Tabela 3: Resultados análise estatística BIOENV: correlação de Spearman.

\begin{tabular}{lll|lll}
\hline \multicolumn{2}{c}{ Altura } & \multicolumn{3}{l}{ Sobrevivência } \\
\hline N.vars & Correlação & Selections & N.vars & Correlação & Selections \\
\hline 2 & 0,248 & $6 ; 7$ & 1 & 0,194 & 14 \\
3 & 0,248 & $6 ; 7 ; 12$ & 2 & 0,194 & $12 ; 14$ \\
1 & 0,243 & 7 & 2 & 0,186 & $14 ; 15$ \\
2 & 0,243 & $7 ; 12$ & 3 & 0,186 & $12 ; 14 ; 15$ \\
1 & 0,170 & 6 & 4 & 0,184 & $7 ; 14 ; 15$ \\
2 & 0,170 & $6 ; 12$ & 2 & 0,184 & $7 ; 12 ; 14 ; 15 ;$ \\
3 & 0,166 & $2 ; 6 ; 7$ & 3 & 0,178 & $7 ; 14$ \\
4 & 0,166 & $2 ; 6 ; 7 ; 12$ & 3 & 0,178 & $7 ; 12 ; 14$ \\
3 & 0,166 & $6 ; 7 ; 13$ & $4 ; 13 ; 14$ \\
4 & 0,166 & $6 ; 7 ; 12 ; 13$ & 4 & 0,178 & $7 ; 12-14$ \\
\hline
\end{tabular}

Variáveis: 1.ph,2. Corg,3.M.O.,4.P,5.Na,6.K,7.Ca,8.Mg,9.Cu,10.Fe,11.Mn,12.Zn,13.areia,14.silte,15.argila.

\section{DISCUSSÃO}

\section{Sobrevivência}

Os resultados mostraram que os meses chuvosos favoreceram a sobrevivência das mudas. Ressaltase que a precipitação média do período chuvoso registrada foi de $503.1 \mathrm{~mm}$ e a média observada na estação seca foi 42,2 mm. Tsuji (2010) em pesquisa na península de Ajuruteua, através de métodos de semeadura direta, mostrou que os resultados para taxas de crescimentos foram maiores para as mudas da espécie $R$. mangle.

É importante destacar que o manguezal da região bragantina na área do Km 17 no lado oeste da estrada é um local degradado e pouco irrigado devido a construção da rodovia PA- 458, essa área foi a mais prejudicada segundo Fernandes et al. (2007), e o trecho foi transformado completamente em uma área alterada, com árvores mortas e poucos indivíduos remanescentes, os quais resistiram ao solo ressecado, hipersalino e exposto à alta radiação solar.

Os efeitos da salinidade e sodicidade observados durante o crescimento das plantas têm sido 
descritos por vários autores (SHANNON et al., 1994). Uma das alternativas encontradas para diminuir os impactos desses solos sobre os vegetais é a aplicação de corretivos que reduzem o excesso de sódio, baixam o $\mathrm{PH}$ e, consequentemente, liberam mais nutrientes às plantas.

De acordo com Barbier et al. (2003) a obstrução dos canais-de-maré para a construção da rodovia (PA 458) interferiu na hidrodinâmica local, promovendo a degradação de uma grande área de manguezal. Em estudo realizado nessa mesma área, a baixa frequência de inundação registrada no local deve ter determinado a existência de uma floresta de mangue, particularmente sensível às perturbações hídricas (LARA et al., 2003).

Um dos efeitos causados pela construção da rodovia PA-458 foi a interrupção da periodicidade do fluxo das marés para a área focal do seu estudo (Área Alterada) e tornou o suprimento de água escasso, promovendo o ressecando do solo (FERNANDES et al., 2007). O autor cita ainda que outra consequência da construção dessa rodovia foi evidenciada nos parâmetros físico-químicos monitorados na área, os quais foram alterados. A salinidade da água de percolação, por exemplo, assumiu valores maiores, certamente em função da ausência de cobertura vegetal e da escassez de água, o que proporcionou maior evaporação e, consequentemente, um excessivo acúmulo de sal. Assim tais condições no presente estudo comprometeram a manutenção e a sobrevivência dessas espécies, acentuando a mortalidade das mudas no período seco da região. Acrescenta-se que na pesquisa não foi realizado suprimento nutricional, embora se conheça a importância dos macro e micronutrientes, como também da granulometria, para o desenvolvimento das espécies florestais de mangue.

Devido a topografia dessas regiões, algumas zonas são inundadas diariamente, enquanto outras são atingidas apenas algumas vezes, em determinadas épocas, pelas grandes preamares de sizígia. Essa variação na frequência de inundação do manguezal pelas marés pode acarretar diferenças nas concentrações de sal, tanto em relação à distância do mar, quanto em relação à fonte de água doce (SCHWENDENMANN, 1998, WOLFF et al., 2000) destaca-se que o KM 17, é inundado somente nas marés de sizígia, corroborando a afirmativa anterior.

A concentração de nutrientes em sedimentos de manguezais são reflexos de muitos fatores, sendo difícil definir a tendência de variações temporais e teor de nutrientes (TAM et al., 1993). Gomes et al. (2017) pesquisando o replantio de espécies arbóreas de mangue em florestas desmatadas na península de Ajuruteua, demonstraram pelos resultados que em função da localização dos blocos, as condições físicoquímicas do solo contribuíram positivamente para o crescimento das mudas das espécies $R$. mangle, $A$. germinas, L. racemosa.

Ao realizar trabalho de replantio de manguezal na Baía de Santo Amaro, estado da Bahia, Orge (1997) avaliou a sobrevivência e comparou altura de folhas, ramos laterais e fixação de propágulos de $R$. Mangle no período de fevereiro de 1994 a dezembro de 1995, e obteve uma taxa de sobrevivência de 60\% e uma altura média de cerca de 70 e $35 \mathrm{~cm}$.

Terrados (1997) investigou o crescimento e sobrevivência de mudas de Rizhophora apiculada e o efeito da acumulação de sedimentos, o Autor demonstrou que a taxa de mortalidade aumenta com a 
acumulação de sedimento nos primeiros meses. O autor também relata que mudas de $R$. Apiculada não tiveram um bom desenvolvimento em áreas costeiras com grandes descargas de nutrientes.

\section{Crescimento}

Em relação ao crescimento em altura, observaram-se valores significativos para o $\mathrm{R}$ global (ANOSIM $R=0,27 ; p=0,01$ ) para o fator mês, indicando a influência positiva dos meses chuvosos nesses parâmetros.

As diferenças nutricionais do solo de abril de 2011 a fevereiro de 2012 (Tabela 02) foram muito pequenas, contudo, os baixos teores minerais encontrados, principalmente fósforo, potássio, sódio, cálcio, magnésio e zinco, associados com a menor pluviosidade no período de agosto a dezembro de 2012, afetaram o crescimento das plantas.

Terrados (1997) no estudo dos manguezais Asiáticos, documentam que o crescimento de mudas Rhizophora apiculata, está diretamente relacionado com nutrientes e sedimentos. O nitrogênio, fósforo e outros sedimentos são essenciais para a regulação do crescimento das mudas. $\mathrm{O}$ autor relata que o crescimento de Rhizophora Apiculada nas bordas é limitado pela quantidade de nutrientes.

\section{Componentes principais}

No primeiro componente foram computados valores mais elevados para as variáveis sódio ( $\mathrm{Na})$ (sódio), Ferro (Fe) e Zn (zinco). No segundo, os componentes que apresentaram correlação positiva foram $\mathrm{PH}$, além de mais duas variáveis físicas, silte e argila. De maneira geral, os cinco fatores das correlações geradas na PCA explicam $59,2 \%$ da variação encontrada para os atributos do solo, indicando gradientes característicos de um solo ácido e pobre em nutrientes, com alta porcentagem de silte e argila.

Silva et al. (2004) em estudo realizado no bosque de Bragança, obtiveram para o primeiro componente maior contribuição cálcio (CA), magnésio) (Mg), argila e salinidade, mostrando que o solo salino e retentor de macronutrientes. No segundo componente os elementos potássio (K) e sódio ( $\mathrm{Na}$ ) apresentaram maior contribuição.

É importante ressaltar que no presente estudo, os blocos foram instalados em um solo degradado, e assim as características físico- químicas do mesmo se constituiraram em um fator limitante para a sobrevivência e crescimento das espécies avaliadas. As espécies arbóreas de mangue podem se desenvolver em uma variedade de substratos, ou seja, de argilosos para areno argilosos (Ferreira et al., 2007).

De acordo com Tam et al. (1993) a retenção e mobilidade de nutrientes no sedimento são influenciadas por características como textura, teor de matéria orgânica, $\mathrm{Ph}$, salinidade, (manganês) Mn, alumínio (Al), ferro ( $\mathrm{Fe})$. Solo com maior percentagem de areia tem menos capacidade de reter matéria orgânica e nutrientes.

Destaca-se que o teor de (M.O) matéria orgânica $(0,09)$ encontrado na área do estudo (Tabela 1) foi bastante reduzido. De acordo com Silva et al. (2004) a M.O (matéria orgânica) junto com a granulométria e o silte formam um gradiente com solo ricos em silte, onde tem grande potenciais de retenção de máteria ogânica (M.O). Observou-se também que o PH do solo variou de 5,8 a 7, 4, havendo uma tendêcia para 
alcalinidade (Tabela 01). A redução na disponibilidade de nutrientes, com a elevação do PH de um solo de reação alcalina, foi observada por Gupta et al. (1987).

As condições físico-químicos do ambiente estuarino é propicio a precipitação dos metais com pH alcalinos e em oposição a sua mobilidade pH ácido (SILVA et al., 2002). Segundo Cintrón et al. (1981) os solos de manguezais normalmente apresentam $\mathrm{pH}$ que variam de 4,8 a 8,8. No presente o pH estudo variou de 5,80 a $7,40$.

\section{Fatores bióticos e abióticos (Bioenv)}

Os elementos sódio $(\mathrm{Na})$, cobre $(\mathrm{Cu})$ e zinco $(\mathrm{Zn})$ tiveram maior influência para a sobrevivência. Para o crescimento em altura das mudas foram os nutrientes potássio (K) e cálcio (Ca) e para a variável diâmetro, o silte foi o sedimento que mais contribuiu.

O teor elevado de sódio ( $\mathrm{Na}$ ) está associado ao período de baixa precipitação pluviométrica, pois nessa época a salinidade do mar se eleva, e consequentemente as áreas que sofrem inundações periódicas apresentam maior concentração desse elemento (MARIUS et al., 1991).

Embora tenha se observado um baixo teor de matéria orgânica $(0,09)$ em função dos atributos edáficos da área experimental, já mencionados, Boto (1984) e Kristensen et al. (1995) afirmam que em condições normais, os solos de mangue recebem insumos elevados de matéria orgânica da vegetação em si e inorgânicos dos nutrientes que são importados do mar. De acordo com Terrados (1997) uma fração substancial do material em partículas finas e nutrientes, fazem a deposição do sedimento que sustenta o ecossistema manguezal.

Poucos trabalhos foram realizados com o intuito de avaliar o binômio solo-planta no litoral paraense, citam-se as pesquisas que abordam a composição mineralógica dos sedimentos da região (BEHLING et al., 2004). Fernandes et al. (2007) mostrou que as espécies de $R$. mangle tendem a se associar com solos mais ácidos do que $A$. germinans, contudo o autor, afirma ainda que é necessário traduzir a distribuição das espécies vegetais, em termos de distribuição de um mosaico de solos.

O solo de manguezal é constituído de minerais, detritos, antigênicos e orgânicos resultado de processos de sedimentação através da vegetação do mangue e de restos de animais, eles viram sedimentos orgânicos muito ricos e importantes para a manutenção do manguezal (Berredo, 2008).

Segundo Cohen et al. (1998) o manguezal paraense possui um solo com altos teores de sais, sódio $(\mathrm{Na})$, cálcio $(\mathrm{Ca})$, magnésio $(\mathrm{Mg})$ e potássio $(\mathrm{K})$ que tem uma influência direta na troca de cátions e condutividade elétrica, a qual se torna elevada na presença desses componentes. Na pesquisa em questão os altos os teores o cálcio $(\mathrm{Ca})$ e magnésio $(\mathrm{Mg})$, contudo percebeu-se a interferência do sódio ( $\mathrm{Na}$ ) e potássio (K) foram elevadas, proporcionando assim alta condutividade e trocas de cátions.

\section{CONCLUSÕES}

A condição físico-química da área impactada associada ao baixo índice pluviométrico registrado no período seco se constituíram em fatores limitantes, e influenciaram negativamente a sobrevivência e o 
crescimento das espécies, e explicaram a razão pela qual a mortalidade das mudas foi crescente ao longo do ano na área experimental.

\section{REFERÊNCIAS}

ABREU, M. M. O.; MEHLIG, U.; NASCIMENTO, R. E. A.; MENEZES, M. P. M.. Análise de composicão florística e estrutura florestal de um fragmento de bosque de terra firme e um manguezal adjacente na península de Ajuruteua, Bragança, Pará. Boletim. Museu. Paraense Emílio Goeldi, v.1, n.3, p.27-34, 2006.

BARBIER, E. B.; COX, M.. Does economic development lead to mangrove loss? A cross-country analysis. Contemporary Economic Policy, v.21, n.4, p.418-432, 2003.

BEHLING, H.; COSTA, M. L.. Mineralogy, geochemistry, and palynology of modern and late Tertiary mangrove deposits in the Barreiras formation of Mosqueiro Island, northeastern Para state, eastern Amazonia. Journal of South American Earth Sciences, v.17, n.4, p.285-295, 2004.

BOTO, K. G.. Waterlogged Saline Soils. In: SNEDAKER, S. C.; SNEDAKER, J. G.. The Mangrove Ecosystem: Research Methods. Paris: Unesco, 1984. p.114-130.

CINTRÓN, G.; SCHAEFFER-NOVELLI, Y.. Introducion de la ecologia delmanglar. São Paulo: Instituto Oceanográfico da Universidade de São Paulo, 1981.

COHEN, M. C. L.; RAMOS, J. F. F. L.; DITTMAR, T.. Factors influencing the variability of $\mathrm{Mg}, \mathrm{Ca}$ and $\mathrm{K}$ in waters of a mangrove creek, in Bragança, North Brazil. Mangroves and Salt Marshes, v.44, p.1-7, 1998.

DIEGUES, A. C.. Ecologia Humana e Planejamento Costeiro. 2 ed. São Paulo: Nupaub-Usp, 2001.

FERNANDES, M. E. B.; FERNANDES, J. S.; MURIEL-CUNHA, J.; SEDOVIM W. R.; GOMES, I. A.; SANTANA, D. S.; SAMPAIO, D. S.; ANDRADE, F. A. G. F. P.; OLIVEIRA, L. B.; BRABO, M. G.; SILVA JUNIOR; M. P.. Efeito da construção da rodovia PA-458 sobre florestas de mangue da Península bragantina, Bragança, Pará, Brasil. Uakari, v.3, n.1, p.55-63, 2007.

FERREIRA, T. O.; OTERO, X. L.; VIDAL-TORRADO, P.; MACÍAS, F.. Effects of bioturbation by root and crab activity on iron and sulfur biogeochemistry in mangrove substrate. Geoderma, v.142, n.1-2, p.36-46, 2007.

GOMES, L. F.; ARAUJO, E. C.; COSTA, E. A. J.; BRAGA, C. F.; FERNANDES, M. E. B.. Replantio de espécies arbóreas de mangue em florestas desmatadas na península de Ajuruteua, Bragança-Pará. Revista Ibero-Americana de Ciências Ambientais, v.8, n.2, p.6-19, 2017.

GUPTA, R. K.; ELSHOUT, V. D. S.; ABROL, I. P.. Effectof pH on $\mathrm{Zn}$ adsorption precipitation reactions in an alkalisoil. Soil Science, Baltimore, v.143, p.198-204, 1987.

INMET. Instituto Nacional de Meteorologia. Meteorológica da Estação de Tracateua. Bragança: INMET, 2012.

KRISTENSEN, E.; HOLMER, M.; BANTA, G. T.; JENSEN, M. H.; HANSEN, K.. Carbon, nitrogen and sulfur cycling in sediments of the Ao Nam Bor mangrove forest, Phuket, Thailand: a review. Phuket Mar Biol Cent Res Bull, v.60, p.37-64, 1995.

LACERDA, L. D.. Os manguezais do Brasil. In: VANNUCCI, M.. Os manguezais e nós: uma síntese de percepções. São Paulo: Edusp, 1999. p.185-196.

LARA, R.; COHEN, M.. Sensoriamento Remoto. In: FERNANDES, M. E. B.. Os Manguezais da Costa Norte Brasileira. São Luís: Fundação Rio Bacanga, 2003. p.142.

MARIUS, C.; LUCAS, J.. Holocene mangrove swamps of west Africa sedimentology and soils. Journal of African Earth Science, v.12, n.1-2, p.41-54, 1991.

MENEZES, G. V.; SCHAEFFER-NOVELLI, Y.; POFFO, I. R. F.; EYSINK, G. G. J.. Recuperação de manguezais: um estudo de caso na baixada santista de São Paulo, Brasil. Brazilian Journal of Aquatic Science and Technology, v.9, n.1, p.6774,2005

MORAES, B. C.; COSTA, J. M. N.; COSTA, A. C. L.; COSTA, M. H. C.. Variação espacial e temporal da precipitação no estado do Pará. Acta Amazônica, v.35, n.32, p.207-214, 2005.

OLIVEIRA, L. P. H.. Recuperação biológica em manguezal na parte oeste da baía de Guanabara. II. Crescimento do manguezal na llha do Pinheiro. Memórias do Instituto Oswaldo Cruz, v.51, p.503-521, 1975.

ORGE, M. D. R.. Crescimento de Rhizophora mangle L. em manguezais sob influência de atividades petroleiras na Baía de Todos os Santos. Acta Botanica Brasilica, v.11, p.295-295, 1997.

PROST, M. T. R.; RABELO, B. V.. Variabilidade fito-espacial de manguezais litorâneos e dinâmica costeira: exemplos da Guiana Francesa, Amapá e Pará. Boletim do Museu Paraense Emilio Goeli, v.8, p.93-121, 1996.

QUERESH, M. T.. Experimental plantation for rehabilitation of mangrove forest in Pakistan. First Report. UNDP/UNESCO regional project for research and training. Programme on man-grove ecosystem in Asia and the Pacific (RAS/86/002). Sindh Forest Department, Government of Sindh, 1990.

SCHAEFFER-NOVELLI, Y.. Manguezal: ecossistema entre a terra e o mar. São Paulo: Caribbean Ecological Research, 1995.

SCHWENDENMANN, L.. Tidal and seasonal variations of soil and water properties in a Brazilian mangrove ecosystem. Thesis (Master of Ressources Engineering) - University of Karlsruhe, Karlsruhe, 1998.

SHANNON, M. C.; GRIEVE, C. C.; FRANCOIS, L. E.. Wholeplantresponse to salinity. In: WILKINSON, R. E.. Plantenvironment interactions. New York, 1994. p.199-244. 
SILVA, W. L.; MATOS, R. H. R.; KRISTHOC, G. C.. Geoquímica e índice de geoacumulação de mercúrio em sedimento de superfície do estuário de Santos, Cubatão. Química nova, 25, n.5, p.753-756, 2002.

SILVA, E. S.; FERNANDES, M. E. B.. Relação entre gradiente vegetacional e atributos do solo nos bosques de mangue do furo grande, Bragança-PA. Boletim do Laboratório de Hidrobiologia, v.17, p.19-27, 2004.

SOUZA FILHO, P. W. M.. Costa de manguezais de macromaré da Amazônia: cenários morfológicos, mapeamento e quantificação de áreas usando dados de sensores remotos. Revista Brasileira de Geofísica, v.23, n.24, p.427-435, 2005.

SPALDING, M.; KAINUMA, M.; COLLINS, L.. World atlas of mangroves. In: A collaborative project of ITTO, ISME, FAO, UNEP-WCMC, UNESCO-MAB, UNU-INWEH and TNC. London: Earthscan, London, 2010. p.319.

TAM, N. F. Y.; WONG, Y. S.. Retention of nutrients and heavy metals in mangrove sediments receiving wastewater of different strengths. Environmental Technology, v.14, n.8, p.719-729, 1993

TERRADOS, J.. The effect of increased sediment accretion on survival and growth of Rhizophora apiculata seedlings. Estuarine, Coastal and Shelf Science, v.45, n.5, p.697-701, 1997.

TSUJI, T.. Sobrevivência e crescimento de plântulas das espécies arbóreas de mangue semeadas em áreas degradadas na península de Ajuruteua-Pará. Dissertação (Mestrado em Recursos Biológicos da Zona Costeira Amazônica) - Universidade Federal do Pará, Bragança, 2010.

VRIES, F. W. T. P.. Learning from bright spots to enhance food security and to combat degradation of water and land resources. In: CONGRESSO BRASILEIRO DE CIÊNCIA DO SOLO, 29. Anais. Ribeiro Preto, 2003.

WOLFF, M.; KOCH, V.; ISAAC, V.. A tropich flow model of the Caeté mangrove estuary (North Brazil) with considerations for the sustainable use of its resources. Estuarine Coastal Shelf Science, v.50, n.6, p.789-803, 2000.

A CBPC - Companhia Brasileira de Produção Científica (CNPJ: 11.221.422/0001-03) detém os direitos materiais desta publicação. Os direitos referem-se à publicação do trabalho em qualquer parte do mundo, incluindo os direitos às renovações, expansões e disseminações da contribuição, bem como outros direitos subsidiários. Todos os trabalhos publicados eletronicamente poderão posteriormente ser publicados em coletâneas impressas sob coordenação da Sustenere Publishing, da Companhia Brasileira de Produção Científica e seus parceiros autorizados. Os (as) autores (as) preservam os direitos autorais, mas não têm permissão para a publicação da contribuição em outro meio, impresso ou digital, em português ou em tradução. 